\title{
Research on the Audit Index System of Recipients in Public Welfare Crowdfunding Based on Kano Model
}

\author{
Ao Chen ${ }^{1, *}$, Jingren Liang ${ }^{2}$, Fan $\mathrm{Ye}^{3}$ \\ ${ }^{1}$ School of Economics, Wuhan University of Technology, Wuhan 430070, China \\ ${ }^{2}$ School of Economics, Wuhan University of Technology, Wuhan 430070, China \\ ${ }^{3}$ School of Management, Wuhan University of Technology, Wuhan 430070, China \\ *Ao Chen.602149616@qq.com
}

\begin{abstract}
With the frequent occurrence of donation fraud in China's public welfare crowdfunding industry, how to accurately identify "who is the most in need of help" has become a key issue.So as to further improve the fairness and rationality of charitable funding and promote the public welfare crowdfunding industry to form a benign sense of social trust.In this paper, the traditional and improved Kano model functional analysis method is used to identify and classify the index attribute, and the priority of importance about the audit index is completed by combining the Better-Worse index analysis method.On the basis of the research on the priority of indicators, relevant reference suggestions on the verification and identification of recipients are put forward, which is helpful for the government to build an effective, scientific and authoritative social operation mechanism of public welfare crowdfunding.
\end{abstract}

Keywords: Public welfare crowdfunding, Social trust, Kano model, Better-Worse index, Importance analysis

\section{INTRODUCTION}

Public welfare crowdfunding is a branch of crowdfunding. It refers to the project sponsor, namely the recipients, releasing fund-raising projects and raising funds through the Internet, and encouraging the project investors, namely the donors, to provide funds through social media and other media. At present, public welfare crowdfunding in China mainly covers such fields as relief for serious diseases, care for left-behind children, assistance for the disabled, etc. In essence, most of public welfare crowdfunding belongs to the category of social welfare, with the meaning of donation. Advocated by the government, public welfare crowdfunding in China has developed in an optimistic situation. With its low conditions, high fund-raising efficiency and breaking time-and-space restriction, it has greatly released the enthusiasm for public welfare, brought good news to the vulnerable groups who are in need of help, and promoted the vigorous development of the public welfare industry. However, as public welfare crowdfunding is still in infancy, public welfare organizations are facing a crisis of trust to some extent due to the difficulty in supervising the flow of donations and frequent fraud incidents. In the final analysis, the root cause of the problem lies in the lack of an authoritative regulatory department and a systematic, scientific and strict funding audit system for recipients in public welfare crowdfunding. Therefore, this paper uses literature research, case analysis, group discussion and questionnaire survey method, integrating Kano model and Better-Worse index to set the relevant indicators in the process of funding audit to the recipients. In addition, attribute identification and importance prioritization are conducted from the perspective of the public, providing useful reference for China to build a perfect social operation mechanism of public welfare crowdfunding in the future.

\section{LITERATURE REVIEW}

\subsection{Crowdfunding}

As a novel way of raising funds, crowdfunding has been discussed in many aspects. In general, scholars' researches on crowdfunding mainly involve on equity crowdfunding and lending crowdfunding. The focus is mostly on the relevant factors and empirical study that affect crowdfunding projects. Scholars use the grounded theory to reveal the role orientation of investors the investment scale, and the relationship between service 
organizations in crowdfunding activities [1]. An online survey of potential donors in North America found that investors tend to give to projects run by nonprofit organizations [2]. Some research findings suggest that participation grows from previous interactions with crowdfunding, other experience is insignificant, and opportunity identification and interactivity on social networks are key factors in the success of crowdfunding campaigns [3].

\subsection{Public Welfare Crowdfunding}

In terms of public welfare crowdfunding, there are relatively few theoretical studies by scholars, mainly focusing on the participation motivation and trust of donors. The rational and credible appeal in the helpseeking information will increase the probability of donation, while the negative emotional appeal alone, or excessive negative emotion, will even reduce the possibility of donation [4]. An analysis of the real experiences of 13 donors to public welfare crowdfunding shows that trust is an influential motivational source for donors' participation motivation [5]. A good strategy for social content design is probably the best way to increase the amount of funding in a charity crowdfunding project [6].

Although "Internet + Public welfare crowdfunding" in China has entered the fast track of development, there is no good solution to the social trust crisis encountered by the industry. Therefore, the research of Chinese scholars in recent years mainly focuses on how to regulate the public welfare crowdfunding industry, including the improvement of legal system, technological innovation and application, platform supervision and management, etc. In terms of the improvement of the legal system, most scholars put forward corresponding legislative suggestions from the perspective of China's Charity Law, such as the qualification examination of recipients and the attribution of funds [7]. Some studies have also demonstrated the necessity and urgency of formulating special laws and regulations from the aspects of the legitimacy, risk of fraud and breach of contract faced by public welfare crowdfunding [8]. In terms of technological innovation and application, the most common combination is blockchain technology. Through analyzing the application of blockchain in public welfare crowdfunding, scholars have summarized the application framework of Internet public welfare crowdfunding platform based on blockchain technology [9]. In addition, the practice has proved that it is feasible. A new charity application model combining blockchain technology has been proposed, and a crowdfunding charity flow platform has been successfully built [10]. In terms of platform supervision and management, according to the research materials of foreign public charity supervision, advocating the construction of multi-dimensional public charity supervision mechanism including platform supervision, public oversight and other elements [11]. A case analysis is conducted from the perspective of trust mechanism of public welfare crowdfunding platforms, and targeted countermeasures are given for the management and trust problems of public welfare crowdfunding platforms [12].

Reviewing the research status of domestic and foreign scholars on public welfare crowdfunding, the research perspective from the recipient's funding audit and verification system is relatively lacking. In view of the gaps in the above studies, we summarized the indicators covered by the system from the perspective of social recognition by means of literature research and case analysis. At the same time, we also constructed Kano Model structured survey questionnaire to classify the attributes of the indexes in the system and prioritized the importance of the indicators based on the BetterWorse index. Relying on the degree of social recognition of the recipients' audit indexes, it will inject energy into the healthy and stable development of the public welfare crowdfunding industry.

\section{KANO MODEL}

In October 1979, On the basis of the hygienemotivational factors theory of American psychologist Frederick Herzberg, Professor Noriaki Kano in Tokyo University of Technology introduced the standard of satisfaction into the field of quality management for the first time and published a research report named "Attractive Quality and Must-be Quality". It marked the establishment of Kano model and the maturity of attractive quality theory. Kano model is a useful tool for indicator demand identification and prioritization. It is a typical qualitative analysis model to characterize the nonlinear relationship between product or service quality and user satisfaction.

According to the subjective perception of users, the model divides the quality characteristics of product services into five attribute types: Must-be Demand, One-dimensional Demand, Attractive Demand, Indifferent Demand and Reverse Demand. Thereinto, Must-be Demand (M) refers to the demand characteristics of a product or service that users take for granted to be provided; One-dimensional Demand (O) refers to the demand characteristics that users have their own requirements for products or services; Attractive Demand (A) refers to the demand characteristics that will surprise users and greatly improve user satisfaction; Indifferent Demand (I) refers to the demand characteristics in which users have no attitude to whether a product or service is provided or not; Reverse Demand $(\mathrm{R})$ is a product or service that the user does not want to possess. The overall model curve can be shown in figure 1 below. 


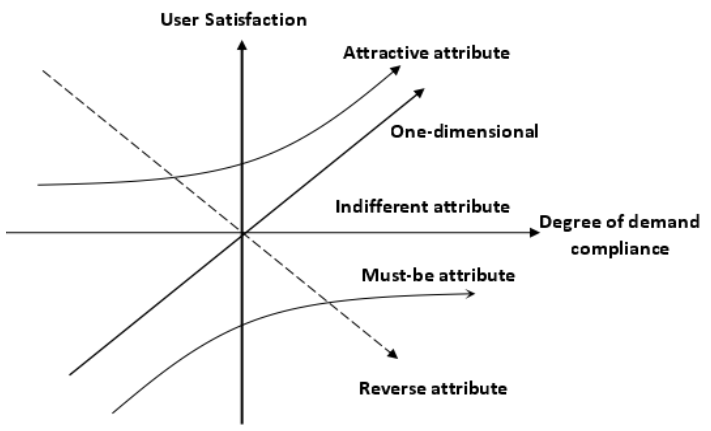

Figure 1 Kano model curve

\section{RESEARCH METHODOLOGY}

\subsection{Research Path}

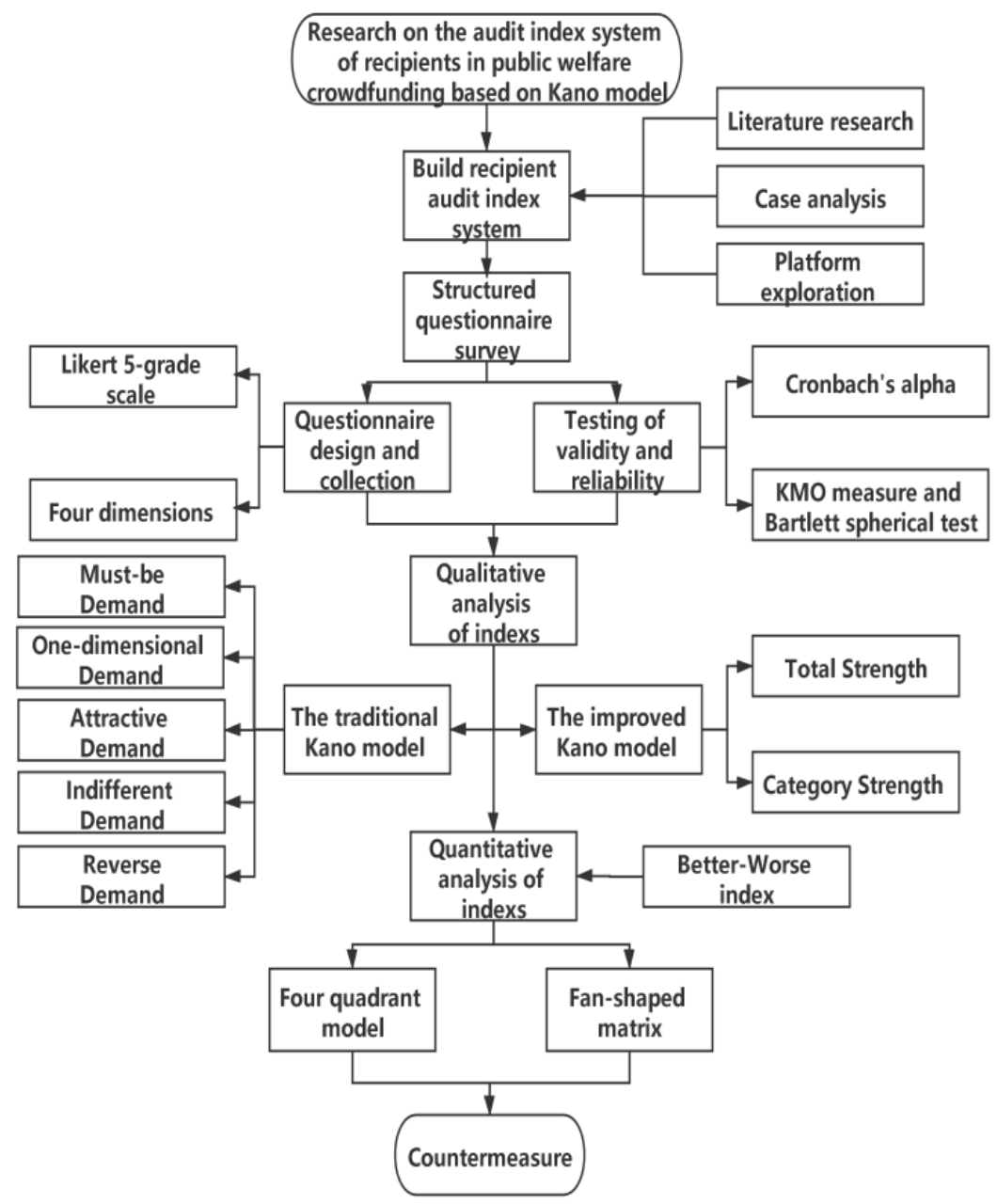

Figure 2 Research path framework

\subsection{Construction of Audit Indexes For Recipients}

Through a large number of public welfare crowdfunding related literature research, we conducted in-depth case analysis of a number of fraud incidents. From the well-known domestic public welfare crowdfunding platforms such as Shuidi Chou, Easy
The main research process can be divided into five steps. First of all, we build a scientific recipient audit index system. Secondly, it is to design and collect Kano model structured questionnaire and test its reliability and validity. The next is to use the traditional and improved Kano model for qualitative analysis of index attribute classification. The fourth step is based on the four quadrant model of Better-Worse index and the fanshaped matrix to carry out quantitative analysis on the importance ranking of social recognition of indicators. At last, we put forward targeted solutions to optimize the trust of the industry according to the analysis results, so as to reduce the probability of donation fraud event. The research path is shown in figure 2 . 
Table 1 Index classification and connotation

\begin{tabular}{|c|c|c|c|}
\hline Index & Connotation & Dimension & Coding \\
\hline Applicant's personal file & $\begin{array}{l}\text { ID card, household register and other materials that briefly } \\
\text { describe the personal status }\end{array}$ & \multirow{3}{*}{$\begin{array}{c}\text { Basic } \\
\text { informatio } \\
n\end{array}$} & A1 \\
\hline Family hardship & $\begin{array}{l}\text { Whether the family belongs to the registered poor } \\
\text { households, low-income households, etc }\end{array}$ & & $A 2$ \\
\hline Past funded history & Applicant's past experience of receiving assistance & & A3 \\
\hline Monthly average consumption & Average monthly expenses for applicant & \multirow{4}{*}{$\begin{array}{l}\text { Economic } \\
\text { burden }\end{array}$} & B1 \\
\hline $\begin{array}{l}\text { Per capita household } \\
\text { disposable income }\end{array}$ & The discretionary income of the applicant's family & & B2 \\
\hline Liability situation & $\begin{array}{l}\text { The detailed description of the applicant's liability } \\
\text { information }\end{array}$ & & B3 \\
\hline Relevant asset information & $\begin{array}{l}\text { The car and house property owned by the applicant's } \\
\text { family }\end{array}$ & & B4 \\
\hline Applicant's disease profile & The subjective description of an individual's illness & \multirow{3}{*}{$\begin{array}{l}\text { Health } \\
\text { condition }\end{array}$} & C1 \\
\hline Applicant's working capacity & Assessment of the applicant's disability and ability to work & & $\mathrm{C} 2$ \\
\hline $\begin{array}{l}\text { Relevant hospital medical } \\
\text { examination report }\end{array}$ & $\begin{array}{l}\text { Applicant's medical record, condition report and other } \\
\text { objective diagnostic results }\end{array}$ & & $\mathrm{C} 3$ \\
\hline Applicant's social reflection & $\begin{array}{l}\text { The economic and credit evaluation opinions of the } \\
\text { applicant issued by the resident or village committee }\end{array}$ & \multirow{4}{*}{$\begin{array}{c}\text { Credit } \\
\text { guarantee }\end{array}$} & D1 \\
\hline Applicant's credit standing & $\begin{array}{l}\text { Whether the government credit investigation blacklist is } \\
\text { included or not }\end{array}$ & & D2 \\
\hline $\begin{array}{l}\text { Guarantor's letter of } \\
\text { commitment }\end{array}$ & $\begin{array}{l}\text { Guarantor's written commitment to the authenticity of the } \\
\text { applicant's information }\end{array}$ & & D3 \\
\hline Personal commitment & $\begin{array}{l}\text { The written commitment by the applicant to ensure the } \\
\text { authenticity of the applicant's information }\end{array}$ & & D4 \\
\hline
\end{tabular}

"very supportive", "for granted", "optional", "slightly

\subsection{Kano Model Structured Questionnaire Survey}

In order to set up a fair and objective evaluation system, the Kano model structured questionnaire was designed based on the 14 indexes. The questionnaire was divided into three parts. The first part is the preface of the questionnaire, which introduces the purpose and use of the survey conducted by us. The second part is about the basic information collection of interviewees, including gender, age, participation experience in public welfare crowdfunding projects, understanding of public welfare crowdfunding industry, etc. The third part is the main content of the questionnaire. Combined with Likert 5-grade scale and Kano questionnaire design method, we ask forward and reverse questions of 14 indicators from four dimensions respectively. A total of 28 questions were asked to measure the respondents' satisfaction and approval degree with and without these indicators in the audit system. The interviewees will choose their satisfaction degree from the five answers of disapprove" and "absolutely opposed".

Prior to the release of the final questionnaire, we conducted questionnaire pre-survey work, revised the expression of relevant content and added guidance to ensure that interviewees understood the connotation of each indicator and the purpose of the survey, so that the questionnaire would have certain significance and the survey results would be scientific and credible. Data collection of the questionnaire survey was carried out from September 2020 to October 2020 through a combination of online and offline distribution. On the Internet, interviewees were invited to fill in the content mainly through the Questionnaire Star, WeChat Moments and other platforms. Offline, the questionnaire interviewees were randomly sought in several university campuses and Hongshan District in Wuhan. Through sorting out, we collected a total of 254 questionnaires. Twenty-five invalid questionnaires were excluded. Because most of the forward and reverse answers were the same "very supportive" or "absolutely opposed", and some of them took too little time to fill in. In the end, 229 valid questionnaires were obtained, and the 
effective rate of questionnaire collection was $90.16 \%$. According to the statistical results of the second part of the questionnaire, the basic information of the interviewee is that there are 124 males and 105 females, with a male to female ratio of about 54:46. The majority of the interviewee's age group is from 20 to 40 years old, accounting for about $90 \%$. Most of them have participated in public welfare crowdfunding projects and have a certain understanding of public welfare crowdfunding. On the whole, this questionnaire survey conforms to the basic principles of questionnaire design, and the data is highly representative and scientific.

In this paper, we use SPSS22.0 software to test the reliability and validity of the collected data, so as to make sure that the statistical results have high stability and consistency. Cronbach's alpha coefficient is used to test the reliability of the internal consistency of the data, and KMO measure and Bartlett spherical test is used to test the validity of the measurement of the data. The statistical analysis results are shown in table 2 . According to the test result of reliability, Cronbach's alpha of forward question is 0.900 , Cronbach's alpha of reverse question is 0.827 , and both forward and reverse coefficient values are higher than 0.8 , so it can be judged that the questionnaire has good reliability. Based on the test result of validity, the KMO coefficient of the forward question is 0.893 , and the KMO coefficient of the reverse question is 0.822 , both of which are higher than 0.8. Meanwhile, the $\mathrm{P}$ value of the Bartlett spherical test is 0.000 , which is less than 0.001 . With showing a significance level, It indicates that the validity of the questionnaire is well. In conclusion, the test results of our Kano questionnaire meet the level of reliability and validity analysis.

Table 2 Reliability and validity test for forward and reverse questions

\begin{tabular}{|c|c|c|}
\hline & Forward question & $\begin{array}{c}\text { Reverse } \\
\text { question }\end{array}$ \\
\hline Cronbach's alpha & 0.900 & 0.827 \\
\hline KMO coefficient & 0.893 & 0.822 \\
\hline The P value & 0.000 & 0.000 \\
\hline
\end{tabular}

\subsection{Qualitative Analysis of Audit Indexes -- The Traditional And Improved Kano Model Functional Analysis Methods}

According to the above-mentioned research path, we classify and identify the relevant indexes in the audit system of public welfare crowdfunding for recipients based on the traditional and improved Kano model functional analysis method. The relationship between the Kano model attribute characteristics of audit indexes and social recognition is shown in table 3 .

Table 3 The explanation of the types of audit attributes for public welfare crowdfunding recipients

\begin{tabular}{|c|c|}
\hline Type & \multicolumn{1}{c|}{ Explanation } \\
\hline Must-be & $\begin{array}{c}\text { Respondents consider attributes that must be included } \\
\text { in the audit system. When the index of Must-be attribute } \\
\text { is included, the public recognition will not significantly } \\
\text { improve. When not included, it will greatly reduce the } \\
\text { public recognition. }\end{array}$ \\
\hline One- & $\begin{array}{r}\text { Respondents consider attributes that should be included } \\
\text { in the audit system. When the index of One-dimensional } \\
\text { attribute is included, the public recognition will be } \\
\text { improved. When not included, it will reduce public } \\
\text { recognition. }\end{array}$ \\
\hline $\begin{array}{r}\text { Attractive } \\
\text { Demand }\end{array}$ & $\begin{array}{r}\text { Indexes of the attribute that are beyond expectation by } \\
\text { respondents. When the index of Attractive attribute is } \\
\text { included, the public recognition will increase } \\
\text { significantly. When not included, it will not result in a } \\
\text { decline in public recognition. }\end{array}$ \\
\hline
\end{tabular}




\begin{tabular}{|c|c|}
\hline $\begin{array}{c}\text { Indifferent } \\
\text { Demand }\end{array}$ & $\begin{array}{c}\text { Respondents consider attributes that may be irrelevant } \\
\text { in the audit system. Whether or not the indexes of } \\
\text { Indifferent attribute is included, it will not affect the } \\
\text { public recognition. }\end{array}$ \\
\hline Reverse & $\begin{array}{l}\text { Indexes of the attribute that are completely contrary to } \\
\text { what respondents think. If the index of reverse attribute } \\
\text { is included in the audit system, it will attract the public } \\
\text { disapproval. When not included, the public recognition } \\
\text { will be improved. }\end{array}$ \\
\hline
\end{tabular}

After processing the questionnaire data, with the help of the classification table of Kano evaluation result (table 4 below, mark "very supportive", "for granted", "optional", "slightly disapproved" and "absolutely opposed" as 1 to 5 in turn.), we summarized and analyzed the frequency of five demand attributes of each indicator under the classification of traditional Kano model. In particular, in addition to the five attributes of the classification table, the classification as "Q" means "suspicious result". It indicates that the interviewees may have a wrong understanding of the contents of the questions, leading to the contradictory situation that the answers are "very supportive" or "absolutely opposed".
Table 4 Classification table of Kano evaluation result

\begin{tabular}{|c|c|c|c|c|c|c|}
\hline \multicolumn{2}{|c|}{} & \multicolumn{5}{|c|}{ Reverse question } \\
\cline { 2 - 7 } & 1 & 2 & 3 & 4 & 5 \\
\hline \multirow{4}{*}{$\begin{array}{l}\text { Forward } \\
\text { question }\end{array}$} & 2 & $\mathrm{Q}$ & $\mathrm{A}$ & $\mathrm{A}$ & $\mathrm{A}$ & $\mathrm{O}$ \\
\cline { 2 - 7 } & 3 & $\mathrm{R}$ & $\mathrm{I}$ & $\mathrm{I}$ & $\mathrm{I}$ & $\mathrm{M}$ \\
\cline { 2 - 7 } & 4 & $\mathrm{R}$ & $\mathrm{I}$ & $\mathrm{I}$ & $\mathrm{I}$ & $\mathrm{M}$ \\
\cline { 2 - 7 } & 5 & $\mathrm{R}$ & $\mathrm{R}$ & $\mathrm{R}$ & $\mathrm{R}$ & $\mathrm{Q}$ \\
\hline
\end{tabular}

Referred to the basic principle of Kano model, we classified each index into the demand attribute with the highest frequency according to the principle of frequency maximization. The statistical results are shown in table 5 .

Table 5 Statistical results based on the traditional Kano model

\begin{tabular}{|c|c|c|c|c|c|c|c|c|}
\hline Dimension & Coding & $M$ & 0 & $A$ & I & $\mathrm{R}$ & $Q$ & type \\
\hline \multirow{3}{*}{ Basic information } & A1 & 47 & 104 & 48 & 25 & 3 & 2 & $\mathrm{O}$ \\
\hline & $\mathrm{A} 2$ & 50 & 81 & 55 & 40 & 0 & 3 & $\mathrm{O}$ \\
\hline & A3 & 6 & 18 & 33 & 167 & 1 & 4 & I \\
\hline \multirow{4}{*}{ Economic burden } & B1 & 88 & 57 & 47 & 31 & 2 & 4 & $M$ \\
\hline & B2 & 119 & 58 & 28 & 13 & 6 & 5 & M \\
\hline & B3 & 112 & 63 & 31 & 19 & 2 & 2 & $M$ \\
\hline & B4 & 97 & 67 & 43 & 19 & 2 & 1 & $M$ \\
\hline \multirow{3}{*}{ Health condition } & $\mathrm{C} 1$ & 128 & 66 & 25 & 8 & 0 & 2 & $M$ \\
\hline & $\mathrm{C} 2$ & 43 & 75 & 63 & 45 & 0 & 3 & $\mathrm{O}$ \\
\hline & $\mathrm{C} 3$ & 5 & 63 & 30 & 121 & 3 & 7 & I \\
\hline \multirow{4}{*}{ Credit guarantee } & $\mathrm{D} 1$ & 2 & 22 & 31 & 165 & 1 & 8 & I \\
\hline & D2 & 88 & 49 & 51 & 37 & 3 & 1 & $M$ \\
\hline & D3 & 37 & 61 & 65 & 60 & 3 & 3 & $A$ \\
\hline & D4 & 42 & 79 & 48 & 56 & 1 & 3 & 0 \\
\hline
\end{tabular}

As can be seen from the results in the table above, no suspicious results or reverse attribute type occur. Belong to the Must-be attribute (M) which is thought necessary index in the system by public, there are six indexes of B1, B2, B3, B4, C1 and D2. When these indicators are not included in the audit process of recipients, it will lead to a great decline in social recognition. All indicators of the economic burden dimension are classified as Must-be attribute, which also shows that the public pays the highest attention to 
the economic situation in public welfare crowdfunding. One-dimensional attribute (O) contains four indicators:A1, A2, C2, and D4. These indicators have a linear relationship with social recognition. Only when a written commitment to ensure the authenticity of the recipients' information is included in the future audit process and system can the trust in the public welfare crowdfunding industry be better enhanced.D3 is the only indicator belonging to Attractive attribute (A), indicating that the guarantor mechanism proposed in this paper is an unexpected design of the public, which can reduce the incidence of donation fraud to a certain extent. Indifferent attribute (I) involves three indexes, namely A3, C3 and D1. The influence of these indicators involved on social recognition is negligible, but it does not mean that we should completely abandon them. Because the Indifferent attribute with a relatively high degree of importance is potentially important quality element, which may be transformed into the Attractive attribute in the dynamic change cycle of the attributes in the Kano model.

It can be found from table 5 that there is no obvious dominant classification of some indicators when they are classified. It can be found from Table 5 that there is no obvious dominant classification of some indicators when they are classified. By referring to the research viewpoints of Lee and Newcomb, the indicator should belong to the demand attribute of mixed class. For the evaluation criteria of mixed attributes, we introduce Total Strength (TS) and Category Strength (CS) to improve the Kano model, and then carried out the secondary attribute classification. For quantitative indicators, TS evaluates whether the setting of an index in the audit system is satisfactory to the interviewees, while CS evaluates the extent to which the interviewees agree with the category belonging to an index in the audit system. When TS is greater than or equal to $60 \%$ and CS is less than $6 \%$, the indicator should be reidentified as a mixed attribute. When CS is greater than $6 \%$, it indicates that there is a significant degree of distinction between categories, so the classification result of attribute under the traditional Kano model should be retained. The relevant calculation formula is as follows.

$\mathrm{TS}=(\mathrm{M}+\mathrm{O}+\mathrm{A}) /((\mathrm{M}+\mathrm{O}+\mathrm{A}+\mathrm{I}+\mathrm{Q}+\mathrm{R})$

$\mathrm{CS}=[\max (\mathrm{M}, \mathrm{O}, \mathrm{A}, \mathrm{I}, \mathrm{Q}, \mathrm{R})$-second $\max (\mathrm{M}, \mathrm{O}, \mathrm{A}, \mathrm{I}, \mathrm{Q}, \mathrm{R})]$

/ $(\mathrm{M}+\mathrm{O}+\mathrm{A}+\mathrm{I}+\mathrm{Q}+\mathrm{R})$

Based on the improved Kano model, the first two attributes with the largest frequency are the main recognition types of mixed attribute. The classification result is written as $(\mathrm{X}+\mathrm{Y})$, where $\mathrm{X}$ and $\mathrm{Y}$ are one of the five attributes under the traditional model. The statistical calculation results are shown in table 6 below.

Table 6 Attribute identification based on the improved Kano model

\begin{tabular}{|c|c|c|c|c|}
\hline Coding & $\begin{array}{c}\text { Traditional } \\
\text { classification }\end{array}$ & TS & CS & $\begin{array}{l}\text { Improved } \\
\text { classification }\end{array}$ \\
\hline $\mathrm{A} 1$ & 0 & 0.869 & 0.245 & 0 \\
\hline A2 & O & 0.812 & 0.114 & O \\
\hline A3 & I & 0.249 & 0.585 & I \\
\hline B1 & $M$ & 0.838 & 0.135 & $M$ \\
\hline B2 & $M$ & 0.895 & 0.266 & $M$ \\
\hline B3 & $M$ & 0.900 & 0.214 & $M$ \\
\hline B4 & $M$ & 0.904 & 0.131 & $M$ \\
\hline C1 & M & 0.956 & 0.271 & M \\
\hline C2 & O & 0.790 & 0.052 & $\mathrm{~A}+\mathrm{O}$ \\
\hline C3 & 1 & 0.428 & 0.253 & 1 \\
\hline D1 & 1 & 0.240 & 0.585 & 1 \\
\hline D2 & M & 0.821 & 0.162 & $M$ \\
\hline D3 & A & 0.712 & 0.017 & $\mathrm{~A}+\mathrm{O}$ \\
\hline D4 & O & 0.738 & 0.100 & O \\
\hline
\end{tabular}

The improved Kano model with the introduction of mixed class analysis makes up for the errors in the classification results and the inaccuracy of attribute identification in the traditional method. The indexes classified as mixed attribute include C2 and D3, and both of them are mixed classification of Attractive and One-dimensional attributes. Therefore, we should comprehensively consider the relationship between Attractive Demend, One-dimensional Demend and social recognition when formulating the audit system. At the same time, note the dynamic change of the indicator type from $\mathrm{A}$ to $\mathrm{O}$.

\subsection{Quantitative Analysis of Audit Indexes -- Better-Worse Index Analysis Method}

Both traditional and improved Kano model functional analysis methods use qualitative methods to identify demend type.In this way, it is impossible to quantitatively analyze the influence characteristics of various audit indexes on social recognition. So as not to accurately judge the influence of an index included or not included in the audit system and process on the public recognition degree.In order to make up for the deficiencies of the above research methods, this paper derived the Better index and the Worse index to evaluate the influence of a certain quality factor on user satisfaction by referring to the Better-Worse index analysis method proposed by Berger and other scholars.In our research, the Better index refers to the effect of providing an indicator factor to improve public recognition, while the Worse index refers to the effect of not providing an indicator factor to reduce public recognition.In general, the absolute values of the Better and Worse indices range from 0 to 1.The specific calculation formula is as follows.

Better index $=(\mathrm{A}+\mathrm{O}) /(\mathrm{A}+\mathrm{O}+\mathrm{M}+\mathrm{I})$

The closer the value of a certain indicator's Better index is to 1 , the greater the degree of recognition of the 
indicator will be enhanced when it is included in the audit system, and the more obvious the positive effect is.

Worse index $=-(\mathrm{O}+\mathrm{M}) /((\mathrm{M}+\mathrm{O}+\mathrm{A}+\mathrm{I})$

The closer the value of a certain indicator's Worse index is to -1 , the greater the degree of recognition of the indicator will be reduced when it is included in the audit system, and the more significant the passive effect is.

In summary, we use the above calculation method to obtain statistical results in table 7.

Table 7 The statistical results of Better-Worse index of audit indicators

\begin{tabular}{|c|c|c|}
\hline Coding & Better index & Worse index \\
\hline A1 & 0.679 & -0.674 \\
\hline A2 & 0.602 & -0.580 \\
\hline A3 & 0.228 & -0.107 \\
\hline B1 & 0.466 & -0.650 \\
\hline B2 & 0.394 & -0.812 \\
\hline B3 & 0.418 & -0.778 \\
\hline B4 & 0.487 & -0.726 \\
\hline C1 & 0.401 & -0.855 \\
\hline C2 & 0.611 & -0.522 \\
\hline C3 & 0.425 & -0.311 \\
\hline D1 & 0.241 & -0.109 \\
\hline D2 & 0.444 & -0.609 \\
\hline D3 & 0.565 & -0.439 \\
\hline D4 & 0.564 & -0.538 \\
\hline The average & 0.466 & -0.551 \\
\hline
\end{tabular}

In order to be more clear and intuitive grasp of the various audit indexes affecting the degree of social recognition, we made data visualization of the statistical results of the Better-Worse index analysis by adopting the four quadrant model. It takes the value of the Better index as the horizontal axis, the absolute value of the Worse index as the vertical axis, and divides it into four quadrants based on the average value of the two indices. The results are shown in figure 3.

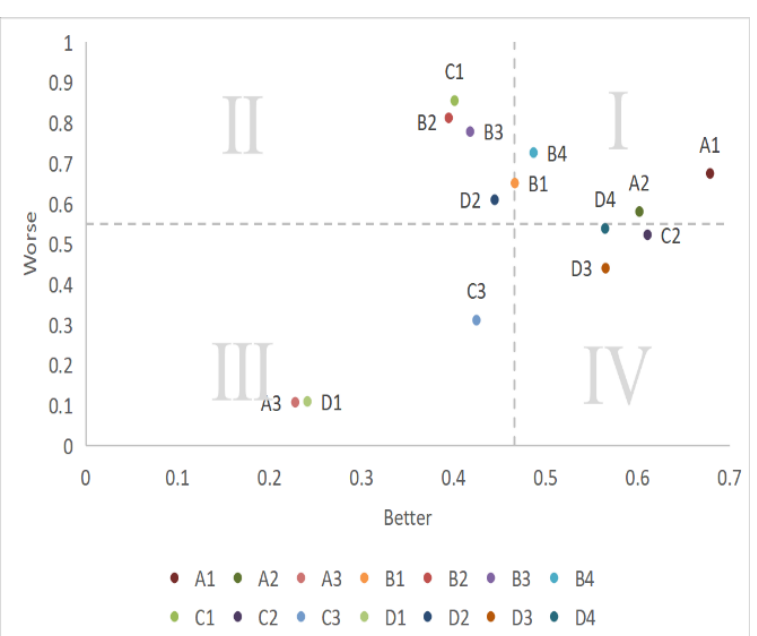

Figure 3 Four quadrant diagram of index distribution

From the quadrant diagram classification result show that the first quadrant involving four indicators:A1, A2, B1 and B4,only covers two dimensions: basic information and economic burden. The indexes belonging to the first quadrant are characterized by high Better index and Worse index, indicating that the inclusion of these indexes in the audit system can greatly improve the public recognition, Otherwise, it will significantly reduce the public recognition.

The second quadrant includes four indicators such as B2, B3, C1 and D2, and the dimension of economic burden is the main one. Belong to the second quadrant of the indexes are characterized by Better index is lower than the average, Worse index is higher than average. It shows that these indicators do not play an obvious role in improving public recognition and optimizing the trust mechanism of crowdfunding. However, if these indicators are not included, they will be significantly disapproved by the public. That is, people take it for granted that there should be second-quadrant indexes in the audit system.

The third quadrant contains three indicators such as A3, C3 and D1, and covers all the indicators of other dimensions except those related to the economic burden dimension. The indexes in the third quadrant are characterized by low levels of both Better index and Worse index. It indicates that whether these indicators are included in the audit system has no obvious effect on the increase of public recognition and the decrease of public suspicion. The correlation characteristics are similar to the Indifferent attribute under traditional classification.

Three indicators, such as C2, D3 and D4, are located in the fourth quadrant, that is, the credit guarantee dimension is the majority. The fourth quadrant is characterized by Better index above average and Worse index below average, similar to the Attractive attribute of traditional classification. Therefore, the indicators 
that meet this quadrant play a significant positive role in improving the social satisfaction and recognition of the audit system. If relevant indexes are included, the social recognition of the audit system will not be reduced.

The Better index and Worse index reflect the relationship between the relevant indicators of the recipients' funding and the public satisfaction.On the basis of the four-quadrant model division mentioned above, in order to further explore the priority ranking of the importance of each index in the audit system, we take the two-dimensional fan-shaped matrix diagram about Better-Worse index as the next analysis tool.The horizontal axis of the matrix figure is the value of the Better index, and the vertical axis is the absolute value of the Worse index, ranging from 0 to 1 . Then, the importance matrix is constructed by drawing an arc from the origin as the center of the circle.The priority order of indicators is determined by the line distance between the original point and the coordinate point of each indicator element.The line distance between the coordinate point and the origin is taken as the importance evaluation standard. The index elements closer to the origin have lower importance.On the contrary, the index elements farther away from the origin have higher importance, that is, they have higher priority, which can be defined as the key index in the audit system.The specific calculation formula is as follow.

$\mathrm{d}=\sqrt{\text { Better }^{2}+\text { Worse }^{2}}$

According to this formula, the two-dimensional fanshaped matrix diagram of the audit indicators for recipient of public welfare crowdfunding industry is drawn, as shown in figure 4.

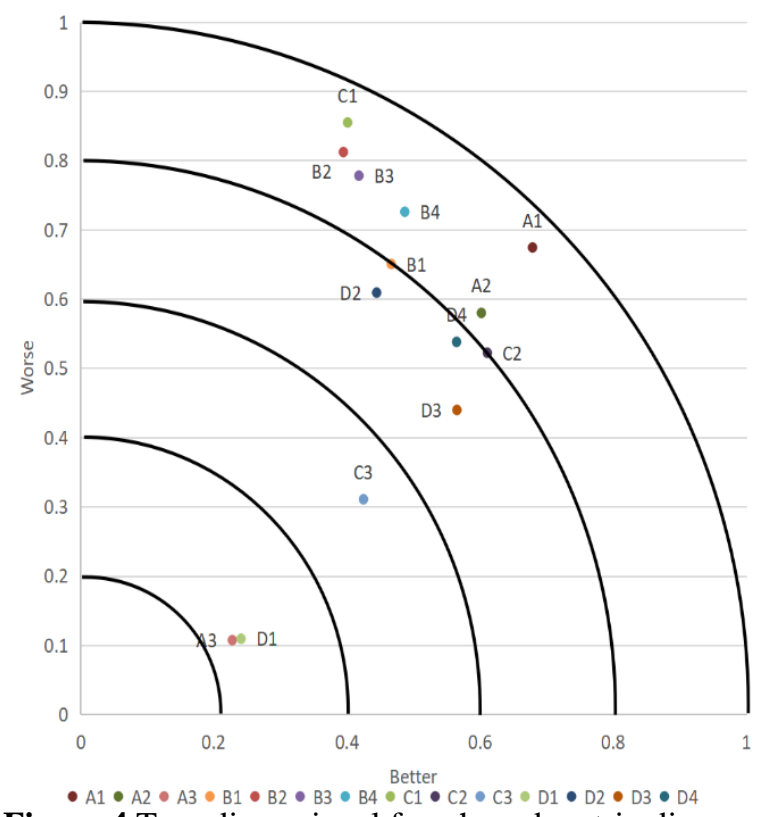

Figure 4 Two-dimensional fan-shaped matrix diagram of Better-Worse index
According to the result in the figure $4, \mathrm{~A} 1$ is the furthest indicator from the origin, followed by $\mathrm{C} 1, \mathrm{~B} 2$, B3 and B4.In terms of importance, the above indicators are the key elements in the audit system of recipients, which can affect the public recognition of the system to a large extent and are of high priority. Similarly, the indicators close to the origin are A3, D1, C3, etc. It indicates that these indicators have a low impact on social recognition, but it does not mean that the indicators are meaningless, unimportant or unnecessary to set. Close attention should be paid to the dynamic and potential importance of the indicators.

\section{RESULTS AND RECOMMENDATIONS}

\subsection{Attribute Recognition Analysis Based On Traditional And Improved Kano Model Functional Analysis Methods}

After the analysis using Kano model functional analysis method, the general principles for the audit index system of recipients in the public welfare crowdfunding industry are as follows: to ensure the inclusion of Must-be Demand index content, optimize to meet One-dimensional Demand index, actively promote the exploration of Attractive Demand index, dynamically observe the change of Indifferent Demand index, and comprehensively consider the characteristics of Mixed Demand index.

Must-be Demand index include applicant's disease profile, per capita household disposable income, liability situation, relevant asset information, monthly average consumption and applicant's credit standing. Combined with the real scene, the cause of trust problems in the public welfare crowdfunding industry is frequent donation fraud incidents, and the most direct link of such incidents is the economic factor. The relevant indicators of economic burden dimension in the audit system proposed in this paper are all divided into Must-be attribute, which also indicates that the current society generally pays attention to the economic status of the recipients. At the same time, it also shows obvious emphasis on the problems such as why the recipients are difficult and whether they are credible. If society is to build a benignant funding operation mechanism, it must make sure that the recipient audit process and the system include the indicators of Mustbe Demand, and there should be stricter audit requirements in this area.

Indexes that belong to the classification of Onedimensional Demand include applicant's personal file, family hardship and personal commitment. Personal information materials such as ID card and household register, as well as the written commitment from the recipients to ensure reliable sources, are needed to build a bridge of trust between strangers. Only when the initial trust is established between the recipient and the 
donor can opportunities for subsequent donations and peer-to-peer support be created. The indicators of Onedimensional Demand are generally the dominant quality elements that generate broad consensus in the society, which requires future funding projects to be good at optimizing and satisfying the social needs in this respect, and to improve and adhere to the correctly oriented public opinion guidance of public welfare crowdfunding

Under the classification of traditional Kano model, the index of Attractive attribute is guarantor's letter of commitment. Since the nature of public welfare crowdfunding is mostly a gratuitous donation, the guarantor related written proof can reduce the immoral behavior of fake public welfare to a certain extent, and enrich the channel of fund traceability. The survey finds that most of the existing online crowdfunding platforms ignored the strong credit endorsement of the guarantor. Therefore, on the premise of meeting the basic and expected needs, the inclusion of indicators related to guarantors in the audit process has strong practical significance. Therefore, on the premise of meeting the Must-be Demand and the One-dimensional Demand, the inclusion of indexes related to guarantors in the audit process has strong practical significance. In the meantime, the small number of indicators of attractive attribute type may also be due to the lack of more extensive effectively index identification, and it is necessary to actively promote the mining work of attractive index elements.

Indifferent type indexes included relevant hospital medical examination report, applicant's social reflection and past funded history. With the rapid development and application of mobile Internet technology, "public welfare crowdfunding + Internet", as an emerging charitable crowdfunding model, has gradually formed a new business form of "fingertip philanthropy". The application of "fingertip philanthropy" also makes most people think that the process of issuing relevant social certificates by residential and village committees is a bit cumbersome, and that the past funded history of recipients cannot affect the social judgment of their funding demand. However, the public cognition of a certain demand will change over time, and the change direction of the category is as follows: $\mathrm{I} \rightarrow \mathrm{A} \rightarrow \mathrm{O} \rightarrow \mathrm{M}$. Indifferent elements may also be potentially important attributes in the audit system, which requires further dynamic monitoring of changes in indexes to better regulate industry development.

After the introduction of mixed analysis to improve the Kano model, the applicant's working capacity and the guarantor's letter of commitment are classified as the mixed attribute of Attractive Demand and Onedimensional Demand. It indicates that the public's emphasis on economic self-sufficiency and credit guarantee materials of recipients is in the process of subtle change. Hence, when disability and guarantor endorsement are included in the management system of public welfare crowdfunding assistance audit, we should comprehensively consider the weight ratio and influence degree of elements in the mixed attribute.

\subsection{The Countermeasure Suggestion Of Recipient Audit Based On Better-Worse Index Analysis Method}

In the public welfare crowdfunding industry, it is very important to accurately find the recipients who "really need help". The indicator factors and evaluation criteria set in the audit are determined by the degree of public recognition, that is, social satisfaction-oriented. Therefore, in order to ensure that the audit indicators we have studied and set are applicable to the public welfare crowdfunding industry, and to maximize the fairness of the funding audit of recipients. We focused on the results of Better-Worse index analysis to severally put forward our suggestions on the qualification and the recognition of recipients from four dimensions.

\subsubsection{Fully Understand The Identity Information Of The Recipients, Combined With Reference To Family Background Conditions}

At present has occurred in the pseudo public welfare events, part of the malignant cases are through the professional writing staff to depict a sad story protagonist. They seize on the social characteristics of poor households, low-income households and farmers, which have always been the most common identity of people at the bottom of the society, in exchange for social sympathy to achieve the purpose of "make use of false difficulties to cheat true money". In the dimension of basic information, the applicant's personal file and family hardship belong to the first quadrant index, and the former is the most important and the highest priority index element affecting social recognition. Similarly, past funded history is the third quadrant, the least influential index. On these grounds, the relevant organization can rely on the ID card is a unique proof of identity, while combining the household register to rationally judge the basic background of their families to prevent the tragic packaging about malicious character identity. Appropriate subsidy preference should be given to recipients whose families are really in difficulty, such as low-income families and poor families. Receiving history and other behavioral experience can only be used as a reference for audit.

\subsubsection{Focus On Checking the Financial Situation Of Recipients To Ensure That "Resources Are Needed"}

As for the emergence of problems such as fund misappropriation and insufficient amount of project 
financing, the root cause is that there is room for optimization and improvement in the current mechanism of public welfare crowdfunding projects. If the fundraising target is set too high and the amount of funds raised fails to reach the expected funding line, then the recipients will not be able to obtain crowdfunding. That is, they will passively drive the recipients to reduce the amount of funds needed, which may lead to the situation that the funding will be a drop in the bucket. From the perspective of third-party public welfare platforms such as Shuidi Chou, their profit model mainly relies on a large number of user flows to sell insurance products. At present, there are loopholes in the judgment of the economic conditions of recipients and the recognition mechanism is not sound. In the dimension of economic burden, relevant asset information and monthly average consumption are in the first quadrant, while per capita household disposable income and liability situation belong to the second quadrant, and they are of high importance and priority. If they are not included in the audit system, social trust risk will be greatly exacerbated. Taking into consideration, it is suggested to focus on the financial situation of the recipients, mainly concentrating upon the evaluation of whether the fund that the recipients are able to flexibly use can afford the medical expenses and the normal living expenses of their families. For public welfare organizations, the possibility and necessity of asset realization should not be ignored, and a prediction model of funding amount of income and expenditure should be established based on project big data. The model includes the liability details, repayment cycle, the ability to make profit independently under the future labor level and other influencing factors. At the same time, we should try our best to set a reasonable amount of funding for each project, adopt a scientific periodic donation cycle and advocate multiple funding rather than one-time payment. Under the above suggestions, the problems of fund misappropriation and traceability can be effectively reduced, which is widely recognized by the society.

\subsubsection{Take an Objective View Of The Health Status Of The Recipients And Guard Against Unrealistic Sentimental Stories}

In the funding projects related to the relief of serious diseases, the real situation of a few patients is not sufficient to make use of social resources for economic support. However, to ease family burdens or save on medical costs, recipients work with "fund-raising consultants" to create emotional stories that exaggerate their own experiences and illnesses so as to motivate people to donate. In the dimension of health condition, the applicant's disease profile, relevant hospital medical examination report and applicant's working ability are respectively in the second, third and fourth quadrant, among which the disease profile is of higher priority.
The disease profile is a general description of the recipient's condition, and it is also the core indicator for donors to understand the crowdfunding project in the short term. Work capacity can be used as a index of ranking of the severity of illness by public among multiple recipients to pinpoint those who "really need help". Although the medical examination report belongs to the third quadrant, its order of importance is relatively higher, which indicates that it is necessary to include the authenticity supporting materials such as hospitalization lists and medical records in the audit system. Therefore, the civil affairs department and other regulatory departments should get involved in crowdfunding projects and grasp the actual conditions of the recipients from a rational and objective perspective. In particular, we must not allow so-called "storytelling" techniques to lead the public to fund projects that do not correspond to the actual situation, which can lead to a significant decline in social trust in the event of misappropriation of fund. In order to prevent false disease materials from passing the qualification examination, the principle of continuity should be followed in the audit process. It is not only necessary to upload the proof of surgery and drug treatment in real time, but also pay attention to the whole process of medical treatment and rehabilitation of the recipients and include it in the audit process.

\subsubsection{Implement The Credit Guarantee Mechanism and Create A Sound Funding Environment}

The occurrence of most public welfare frauds and disputes is due to the intensification of conflicts caused by serious information asymmetry. With the introduction of the Charity Law in 2016, marks that China's public philanthropy has entered the track of rule of law. However, there are only a few laws and regulations to refer to, and there are no legislative constraints on the operation mechanism, scope of funding, information disclosure and other aspects of public welfare crowdfunding. As a result, fraud and crime costs of illegal recipients are low. From the perspective of the result of Better-Worse index analysis method, in the dimension of credit guarantee, personal commitment, applicant's credit standing and guarantor's letter of commitment have a significant impact on social trust in the public welfare crowdfunding industry. Among them, the personal commitment and the applicant's credit standing are given high priority, which also reflects the public's attention to whether there is a written commitment material and related personal credit report in the audit. The source of information asymmetry lies in the absence of credit investigation. We believe that the audit of crowdfunding projects of recipients should be linked with the personal credit investigation system as soon as possible to build a shared credit database. At the same time, a strict trust- 
breaking punishment mechanism should be set up. Once there are illegal acts such as fund misappropriation and information falseness, the violator should be directly listed in the credit investigation blacklist to achieve the role of beforehand deterrence and afterwards accountability. For guarantors, it is necessary to fully explore the role of guarantors in credit guarantee, innovate the multi-guarantor mechanism, optimize the beneficiary audit system as far as possible, and ensure the authenticity of the recipients more comprehensively. Through the cooperation of authoritative institutions, we can innovate the multi-guarantor mechanism, optimize the beneficiary audit system as much as possible, and ensure the authenticity of the recipients more comprehensively. The existence of guarantor is also a way to trace the roots of the recipients, and reduce credit risks. To sum up, the implementation of a system of credit guarantee mechanism is an essential part to create a good funding ecosystem.

\section{CONCLUSION}

This paper carries out related research on the audit of public welfare crowd-funding recipients, and puts forward the index construction content of the audit system. In study, the 14 indexes in the audit system are divided into five types, Must-be Demand, Onedimensional Demand, Attractive Demand, Indifferent Demand and Mixed Demand, mainly through the qualitative method of Kano model. In addition, a quantitative method of Better-Worse index was used to explore the influence of relevant factors on social satisfaction and trust in the public welfare crowdfunding industry. In the end, we summarized countermeasures and suggestions to help the public welfare crowdfunding industry step into a stable and orderly development from four aspects: identity information, financial situation, healthy condition and credit guarantee. The above research provides a reference for the introduction of a scientific and reasonable qualification audit model for recipients in the future, so as to enhance the social credibility of public welfare organizations.

\section{ACKNOWLEDGMENTS}

National innovation and entrepreneurship training program for college students 202010497045.

\section{REFERENCES}

[1] Pizzetti, M., Parasuraman, A., Ordanini, A., \& Miceli, L. (2011). Crowd-funding: transforming customers into investors through innovative service platforms. Journal of Service Management, 22(4), 443-470.

[2] Dragojlovic, N., \& Lynd, L. D. (2016). What will the crowd fund? Preferences of prospective donors for drug development fundraising campaigns. Drug Discovery Today, 21(12), 1863-1868.
[3] Levin, F. (2015). Success determinants of crowdfunding projects. Review of Business and Economics Studies, 3(4), 79-87.

[4] Majumdar, A., \& Bose, I. (2018). My words for your pizza: An analysis of persuasive narratives in online crowdfunding. Information \& Management, 55(6), 781-794.

[5] Bagheri, A., Chitsazan, H., \& Ebrahimi, A. (2019). Crowdfunding motivations: A focus on donors' perspectives. Technological Forecasting and Social Change, 146, 218-232.

[6] Lee, D., \& Park, J. (2020). The relationship between a charity crowdfunding project's contents and donors' participation: An empirical study with deep learning methodologies. Computers in Human Behavior, 106, 106261.

[7] Yao, J. F. (2019). Legal Dilemmas and Solutions of Online Public Welfare Crowdfunding -- From the Perspective of China's Charity Law. Legal System and Society, (15), 33-34+57.

[8] Liu, Y. (2019). Identification and prevention of legal risks in public welfare crowdfunding. People's Tribune, (29), 110-111.

[9] Cai, M. Z., Wang, L., \& Wu, J. (2020). Research on the application of blockchain technology in the field of Internet public welfare crowdfunding. Library and Information, (2), 76-80.

[10] Li, Q., Li, Q., Zhu, J. M., Guan, X. Y., Wang, H., \& Qie, C. Z. (2017). Blockchain-based charity application model and platform. Journal of Computer Applications, 37(S2), 287-292.

[11] Zhao, W. P., \& Chen, B. Z. (2019). The development trend of foreign public welfare and charity supervision and its enlightenment to China. The Journal of Shanghai Administration Institute, 20(6), 91-99.

[12] Xu, K. B. (2020). Research on Trust Mechanism of Public Welfare Crowdfunding Platform, Qingdao University.

[13] Kano, N., Scraku, N., Takanashi, F., et al. (1984). Attractive quality and must-be quality. The Journal of the Japanese Society for Quality Control, 14(2), $39-48$.

[14] Lee, M. C., \& Newcomb, J. F. (1997). Applying the Kano Methodology to Meet Customer Requirements: NASA's Microgravity Science Program. Quality Management Journal, 4(3), 95106.

[15] Berger, C., Blauth, R., Boger, D., et al. (1993). Kano's methods for understanding customerdefined quality. Center for Quality Management Journal, (4), 3-36. 